\title{
Upper cervical spine reconstruction using customized 3D-printed vertebral body in 9 patients with primary tumors involving C2
}

\author{
Feng Wei", Zhehuang Li", Zhongjun Liu, Xiaoguang Liu, Liang Jiang, Miao Yu, Nanfang Xu, \\ Fengliang Wu, Lei Dang, Hua Zhou, Zihe Li, Hong Cai \\ Department of Orthopedics, Peking University Third Hospital, Beijing 100191, China \\ Contributions: (I) Conception and design: F Wei, Z Li; (II) Administrative support: Z Liu, L Jiang; (III) Provision of study material of patients: F Wei, \\ L Jiang, Z Liu; (IV) Collection and assembly of data: Z Li, N Xu; (V) Data analysis and interpretation: F Wei, Z Li; (VI) Manuscript writing: All \\ authors; (VII) Final approval of manuscript: All authors. \\ \#These authors contributed equally to this work. \\ Correspondence to: Zhongjun Liu, MD. Department of Orthopedics, Peking University Third Hospital, Beijing 100191, China. \\ Email: zjliu@bjmu.edu.cn.
}

Background: Reconstruction following resection of the primary tumors of the upper cervical spine is challenging, and conventional internal implants develop complications in this region. 3D printing, also known as additive manufacturing, can produce patient-specific porous implants in a particular shape for bone defect reconstruction. This study aimed to describe the clinical outcomes of upper cervical spine reconstruction using customized 3D-printed vertebral body in 9 patients with primary tumors involving C2.

Methods: Patients with primary tumors involving C2 who were treated in our institution between July 2014 and November 2018 were enrolled. A two-stage intralesional spondylectomy was performed using the posterior-anterior approach. Anterior reconstruction was accomplished using a customized 3D-printed vertebral body, which was fabricated by successive layering of melted titanium alloy powder using electron beam melting. No bone graft was used.

Results: Nine patients ( 2 males and 7 females) were included in the study with a mean age of 31.4 years (12 to 59 years). Seven patients demonstrated tumors located in C2 and 2 showed involvement of C2 and C3. During a mean follow-up of 28.6 months (range, 12-42 months), 1 patient died of systemic metastasis and 1 had local tumor recurrence, the other 7 patients were alive and functional in their daily living until the last follow-up without evidence of disease. The 3D-printed vertebral bodies were all stable with no sign of displacement or subsidence, evidence of implant osseointegration was observed on the imaging studies. For the posterior instrumentation systems, no screw loosening or rod breakage was found.

Conclusions: Spinal reconstruction in the upper cervical region using customized 3D-printed vertebral body is reliable. The tailored shape matching with the contact surfaces and the porous structure conductive to osseointegration provide both short- and long-term stability to the implant.

Keywords: Patient-specific implant; primary spine tumor; spinal reconstruction; total spondylectomy; 3D printing

Submitted Dec 12, 2019. Accepted for publication Feb 05, 2020.

doi: 10.21037/atm.2020.03.32

View this article at: http://dx.doi.org/10.21037/atm.2020.03.32 


\section{Introduction}

Primary osseous spinal tumors are rare and comprise only about $5 \%$ of all primary bone tumors (1). After resection of the tumor, the load-bearing structures of the affected segment are removed, resulting in severe instability. Robust reconstruction is needed to restore the integrity and stability of the spine. The C1-C2 complex is responsible for transition of the axial loading force from the cranium to the spinal column. The unique biomechanical function makes reconstruction in this region challenging $(2,3)$. Instrumentation related complications, such as construct subsidence, migration, and nonfusion are not uncommon owing to a lack of optimal implant (3-7). Novel technology is therefore in demand to help spine surgeons perform safer and more adequately planned surgeries. Three-dimensional (3D) printing, also known as additive manufacturing, refers to the process of fabricating a physical model through successive layering of powder-like materials (including Ti6Al4V, cobalt-chromium alloy, and stainless steel) based on a volumetric digital image generated by computer-aided design (CAD). It can fabricate an implant tailored to the specific anatomy of the individual patient in a controllable manner to enhance the primary immediate postoperative stability. It can also produce size-controllable micropore structures, which can lower the elastic modulus of the metals, decrease the stress shielding at the solid parts of the implant, and promote integration between metal and bone at the contact surface. Since our publication on the first case of $3 \mathrm{D}$-printed vertebral body replacement in January 2016 (8), related use of this technology has started to attract significant interests (9-11). The present study aimed to assess its effectiveness and safety by summarizing the observations in a series of 9 patients undergoing spinal reconstruction using $3 \mathrm{D}$-printed patient-specific implants with a mean follow-up of 28.6 months.

\section{Methods}

\section{Patients}

From July 2014 to November 2018, patients with a primary lesion involving $\mathrm{C} 2$ who underwent $\mathrm{C} 2$ spondylectomy with upper cervical reconstruction using customized 3D-printed vertebral bodies were included in this retrospective study. Pathological diagnosis was established by preoperative computed tomography (CT)-guided biopsy. The study was approved by the institutional review board. Patient age, sex, tumor histology, previous treatment history, and decision- making details were obtained from the medical records and a multidisciplinary team platform. The Enneking system was used for tumor staging (12). The American Spinal Injury Association Impairment (ASIA) Scale (13) was used for motor function rating. The Eastern Cooperative Oncology Group (ECOG) system (14) was used for evaluation of the performance status. The follow-up protocol included physical and radiographic examination, including X-ray, CT scan, and magnetic resonance imaging (MRI) every 3 months for the first year, every 6 months for the second year, and yearly thereafter. The achievement of osseointegration was defined when new bone formation was observed around the bone-implant interface (Figure 1). The postoperative segment height was measured on the midsagittal reconstruction CT from the anterior tubercle of the atlas to the lower endplate midpoint of the caudal body (Figure 1C).

\section{Design of the implant}

Prior to surgery, a $1 \mathrm{~mm}$ thin-layer CT scan of the target spine was performed. The DICOM (Digital Imaging and Communications in Medicine) data were imported into MIMICS 15.0 software (Materialise, Leuven, Belgium) for implant design. Based on the CAD model, the porous metal scaffold implant was fabricated by successive layering of the melted titanium alloy powder (Ti6Al4V, particle size, 45$100 \mu \mathrm{m}$ ) using electron beam melting (Arcam EBM System, AK MEDICAL). The above process took approximately 7 days. Based on our previous studies, the parameters set for the trabecular structure and the size of the uniform micro-pores were determined to generate the optimized biomechanical and osteoinductive properties $(8,15,16)$. The upper contact surface morphology of the implant coincided with the inferior articular surfaces of $\mathrm{C} 1$, while the lower contact surface morphology coincided with the upper endplate of the caudal vertebra (Figure 2).

\section{Surgery}

Based on our experience, we adopted the posterioranterior approach of the staged intralesional spondylectomy to achieve gross total resection as it provides better intraoperative stability and simplifies the surgical technique by reducing the risk of major complications (5). In the firststage surgery, a posterior midline approach was adopted, the posterior elements (laminae, facets, and the posterior and lateral wall of the transverse foramen) and any tumor 

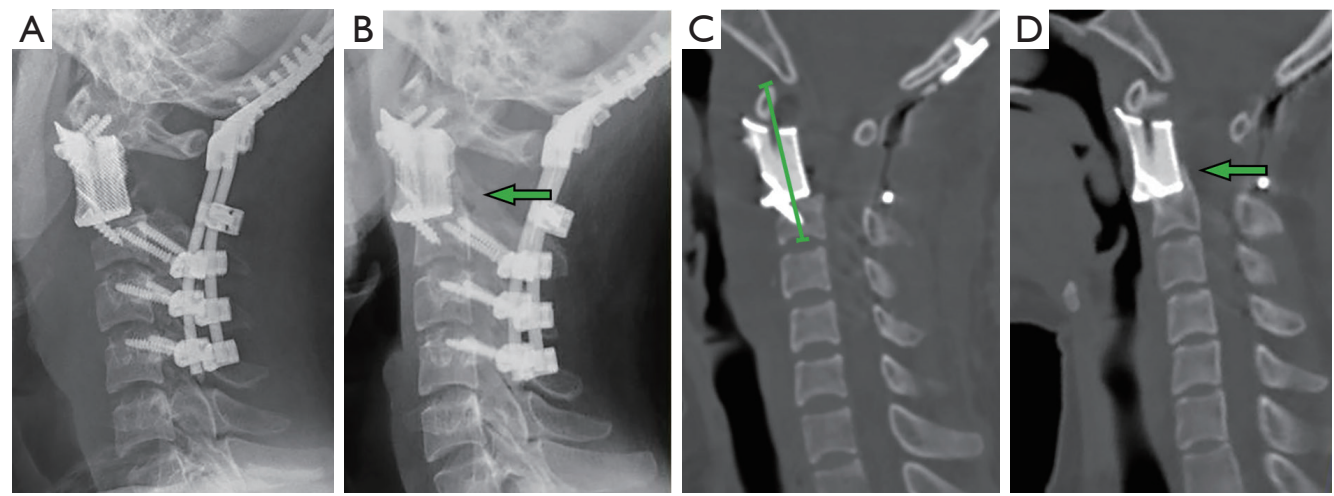

Figure 1 Imaging studies for patient \#3. The achievement of osseointegration was defined when new bone formation was observed around the bone-implant interface on X-ray (B) and CT (D) during the follow-up compared to that of immediately postoperative (A,C). The postoperative segment vertebral height was measured on the midsagittal reconstruction CT from atlas anterior tubercle to the midpoint of the adjacent lower endplate $(\mathrm{C})$.

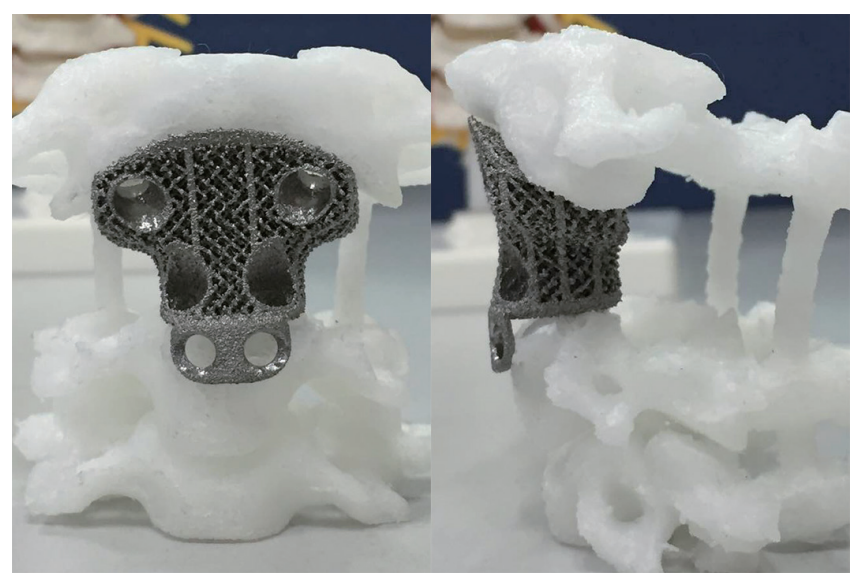

Figure 2 The 3D-printed artificial vertebral body with porous metal scaffold fabricated by successive layering of melted titanium alloy powder.

tissue mass were resected after extracapsular exposure. The vertebral arteries were planned to be preserved. Posterior fixation was performed using the lateral mass screw system. A second-stage anterior high retropharyngeal approach was performed when the patient's physical condition was stable. The integrity of the tumor capsule was preserved as far as possible until the edges were clearly exposed. Once achieved, the tumor and the involved vertebral body were removed piecemeal. Thereafter, the $3 \mathrm{D}$-printed implant was placed. No allograft or autograft was used.

\section{Results}

\section{Baseline characteristics}

A total of 9 patients ( 2 males and 7 females) were included in the study, and their demographic and clinical characteristics were summarized in Table 1 . The patient ages ranged from 12 to 59 years (mean age 31.4 years). Four patients demonstrated giant cell tumors (GCT), 2 had chordoma, 1 had Ewing sarcoma, 1 had paraganglioma, and 1 had aggressive hemangioendothelioma. The diagnoses were established using CT-guided biopsy. The average duration since the onset of symptoms was 2.7 months. Aggravating pain was the initial and common complaint in all patients with a mean visual analog scale (VAS) of 7.1, while neurological impairment was found in 2 patients with ASIA D. According to the Enneking staging system, 4 tumors were graded as S3, 3 tumors as IIB, and 2 as IB. The lesions were lytic in all cases and pathological fractures were identified in 4 patients. Among the 9 cases, 6 presented tumors involving $\mathrm{C} 2$ and 2 with $\mathrm{C} 2$ and $\mathrm{C} 3$ involvement. Vertebral artery involvements were found in 7 cases, 4 bilaterally and 3 unilaterally.

\section{Treatment}

The average interval between the posterior and anterior procedures was 14.4 days. The mean operative time was 449 minutes (range, 356-559 minutes), and the mean blood loss was $1,894 \mathrm{~mL}$ (range, 300-6,400 mL). In the first 4 cases in this series, occipitocervical fixation was performed (Figure 2). Subsequently, with more confidence in the stability of the $3 \mathrm{D}$-printed anterior construct, we were able to preserve the atlanto-occipital joint in the next 
Table 1 The details of the 9 patients

\begin{tabular}{|c|c|c|c|c|c|c|c|c|c|c|c|c|c|c|c|c|c|c|c|}
\hline \multirow{2}{*}{ No. } & \multirow{2}{*}{$\begin{array}{l}\text { Age/ } \\
\text { sex }\end{array}$} & \multirow[b]{2}{*}{ Histology } & \multirow{2}{*}{$\begin{array}{l}\text { Involved } \\
\text { level }\end{array}$} & \multirow{2}{*}{$\begin{array}{l}\text { Enneking } \\
\text { stage }\end{array}$} & \multicolumn{2}{|c|}{ ASIA } & \multicolumn{2}{|c|}{ ECOG } & \multicolumn{2}{|c|}{ VAS } & \multirow{2}{*}{$\begin{array}{l}\text { Follow-up } \\
\text { (months) }\end{array}$} & \multirow{2}{*}{$\begin{array}{l}\text { Final } \\
\text { status }\end{array}$} & \multirow{2}{*}{$\begin{array}{l}\text { Total operative } \\
\text { time (min) }\end{array}$} & \multirow{2}{*}{$\begin{array}{l}\text { Estimated blood } \\
\text { loss (mL) }\end{array}$} & \multirow[b]{2}{*}{ Complications } & \multirow{2}{*}{$\begin{array}{l}\text { Hospital duration } \\
\text { (day) }\end{array}$} & \multirow{2}{*}{$\begin{array}{l}\text { Adjuvant } \\
\text { therapy }\end{array}$} & \multicolumn{2}{|c|}{ Segment height (mm) } \\
\hline & & & & & Preoperative & Final follow-up & Preoperative & Final follow-up & Preoperative & Final follow-up & & & & & & & & $\begin{array}{l}\text { Immediately } \\
\text { postoperative }\end{array}$ & At final follow-up \\
\hline 1 & $12 / \mathrm{M}$ & Ewing sarcoma & C2 & IIB & D & Died & 3 & 5 & 8 & Died & 15 & DOD & 541 & 1,400 & None & 33 & $\mathrm{RT}$ and $\mathrm{CHT}$ & 53.1 & 53.2 \\
\hline 2 & $24 / \mathrm{F}$ & GCT & C2 & s3 & D & E & 3 & 0 & 5 & 0 & 42 & NED & 395 & 300 & None & 25 & RT & 45.3 & 45.0 \\
\hline 3 & $17 / \mathrm{F}$ & GCT & C2 & S3 & E & $\mathrm{E}$ & 3 & 0 & 10 & 1 & 41 & NED & 451 & 3,300 & None & 20 & RT & 50.5 & 50.1 \\
\hline 4 & $47 / \mathrm{F}$ & Paraganglioma & C2 & IIB & E & E & 4 & 1 & 6 & 2 & 39 & NED & 356 & 1,600 & None & 14 & $\mathrm{RT}$ and $\mathrm{CHT}$ & 54.5 & 54.4 \\
\hline 5 & $44 / \mathrm{M}$ & Hemangioendothelioma & C2-C3 & IIB & E & E & 3 & 1 & 9 & 2 & 34 & NED & 559 & 6,400 & None & 37 & RT & 52.9 & 52.6 \\
\hline 6 & $18 / \mathrm{F}$ & GCT & C2 & s3 & E & E & 3 & 0 & 6 & 0 & 32 & NED & 366 & 750 & None & 49 & RT & 43.1 & 43.0 \\
\hline 8 & $16 / \mathrm{F}$ & GCT & C2 & s3 & E & E & 4 & 0 & 9 & 0 & 15 & NED & 432 & 500 & None & 30 & RT & 48.9 & 48.4 \\
\hline 9 & $46 / \mathrm{F}$ & Chordoma & C2-C3 & IB & E & E & 2 & 0 & 4 & 0 & 12 & NED & 485 & 1,700 & $\begin{array}{l}\text { CSF leakage, poor } \\
\text { wound healing }\end{array}$ & 30 & RT & 66.8 & 66.0 \\
\hline
\end{tabular}

GCT, giant cell tumor; DOD, died of the disease; NED, no evidence of disease; AWD, alive with disease; RT, radiation therapy; CHT, chemotherapy; CSF, cerebrospinal fluid. 

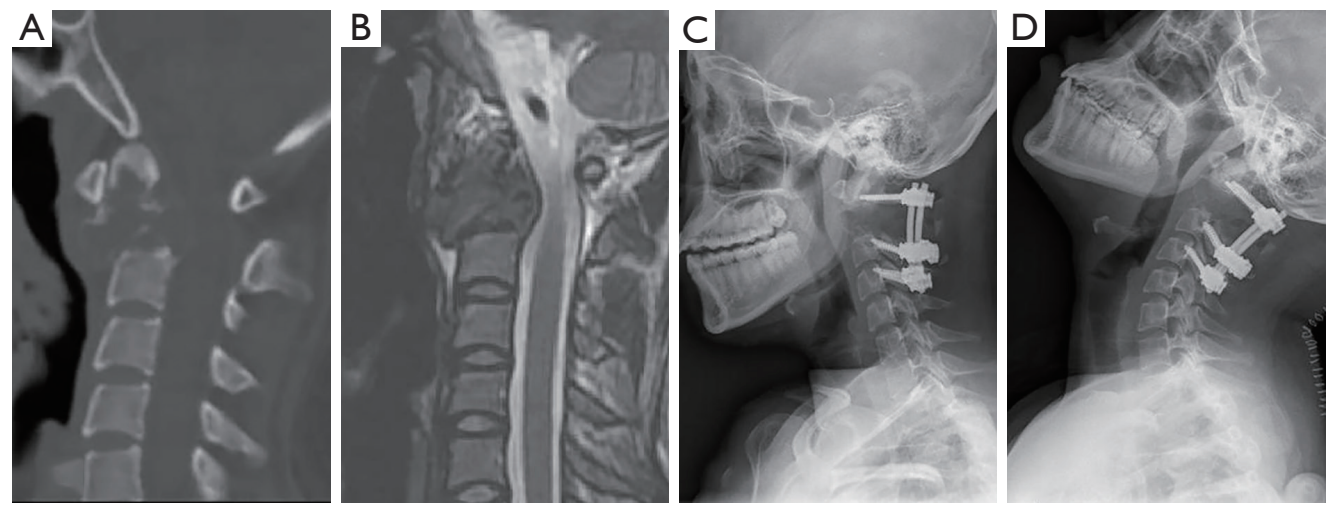

Figure 3 Imaging studies for patient \#6. Preoperative CT (A) demonstrates lytic lesion involving C2 vertebra. Preoperative MRI (B) reveals paravertebral soft tissue involvement. Radiograph after first-stage posterior surgery with occipitocervical joint preserved (C) shows full extension of the mandible to facilitate the anterior high retropharyngeal approach during the second-stage surgery (D).

5 cases (Figure 3). The placement of the distal screws was not performed exactly as planned in 2 patients because the screwdriver was blocked by the mandible with the head of the patient in hyperextension. In patient one, a titanium wire was used for distal fixation. In patient two, only 1 distal screw was placed. One patient suffered posterior incision poor healing caused by cerebrospinal fluid leakage and successfully treated by debridement surgery.

\section{Postoperative recovery}

Our first case, patient one, was a 12-year-old adolescent with a history of asthma. For conservative purposes, we performed tracheotomy before the second-stage surgery to prevent pharyngeal complications and respiratory compromise associated with the anterior approach. He was transferred to the intensive care unit (ICU) and remained ventilator-dependent until postoperative day $(\mathrm{POD}) 4 \mathrm{He}$ was able to ambulate on POD 7 with sternal-occipitalmandibular orthosis, which was replaced by a cervical collar 1 month later. None of the other 7 patients had tracheotomy or ICU stay, and they were permitted to ambulate on POD 1 after the second-stage surgery with the protection of a Philadelphia collar for 1 month.

\section{Outcomes}

The median follow-up was 28.6 months (range, 12-42 months). All patients received postoperative radiotherapy, 2 patients also received chemotherapy. Patient one died of systemic metastases 15 months postoperatively without signs of local recurrence. Patient seven had tumor local recurrence. The others were alive and functional in their daily livings at the last follow-up without evidence of disease. At their final follow-ups, the neurological status of all alive patients was ASIA E, and the average VAS score was 0.9. Three patients had ECOG 1, while 5 patients had ECOG 0 for their general well-being and activities of daily life. During the follow-up, new bone formation was observed around the bone-implant contact surfaces in all patients on the radiograph and CT examinations (Figures $2 B, D, 4 B, C, E, F$ ) which provided the evidence of osseointegration. Further, the $3 \mathrm{D}$-printed vertebral bodies were stable with no signs of implant displacement or subsidence. For the posterior instrumentation systems, no screw loosening or rod breakage was found.

\section{Discussion}

In this study, we assessed the effectiveness and safety of spinal reconstruction using three-dimensional (3D)-printed patient-specific implants in upper cervical region in a series of 9 patients. Osseointegration was observed in all patients with no signs of displacement or subsidence.

Upper cervical reconstruction after complete resection of the tumor is challenging. The unique anatomical structure and biomechanical function of the C1-C2 complex make it difficult with the current techniques (3). The lack of immediate local stability often leads to early instrumentation failure. Rhines et al. (4) reported a case of $\mathrm{C} 2-\mathrm{C} 4$ chordoma, where the anterior construct was performed using fibular allograft combined anterior cervical 

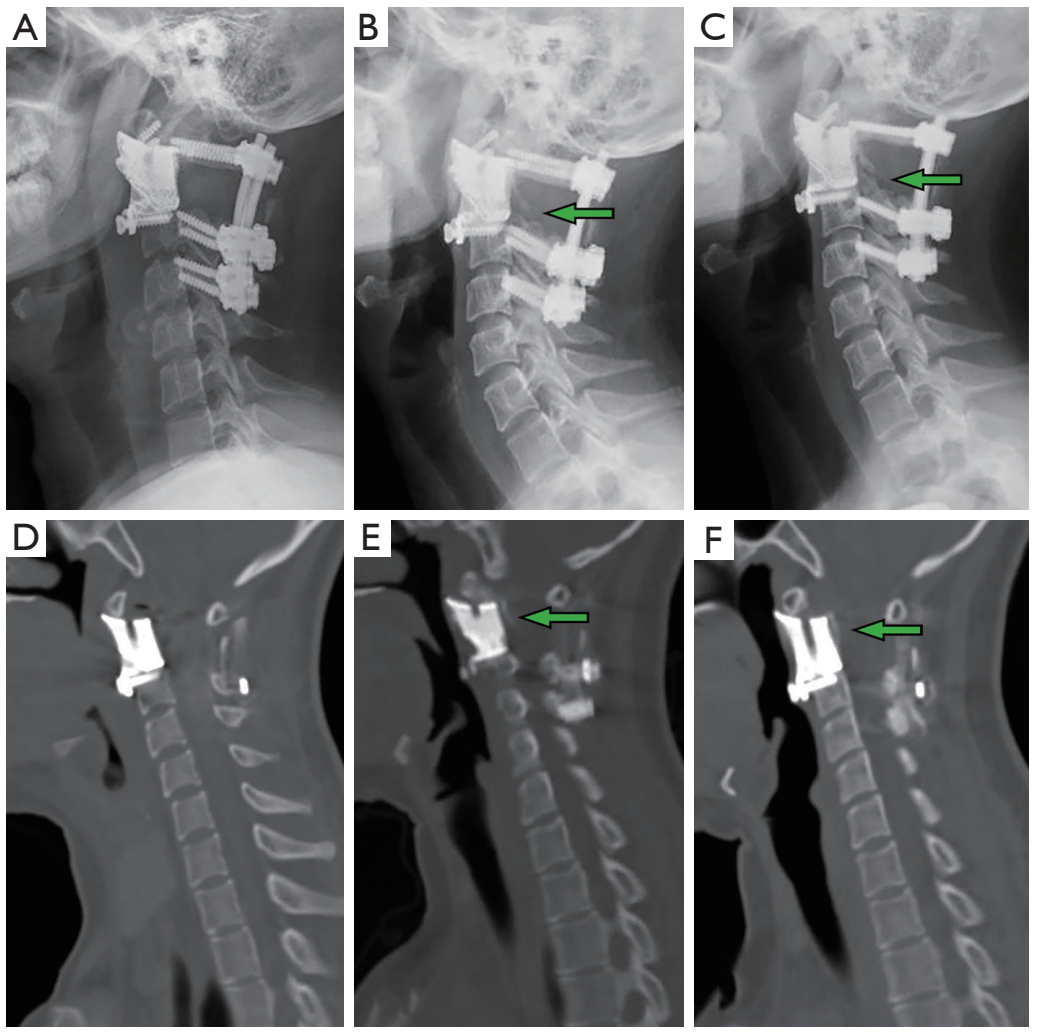

Figure 4 Imaging studies for patient \#6 showing the process of fusion. Compared to the immediate postoperative X-ray (A) and CT (D), regenerated osseous tissue can be seen to gradually grew along the implant 12 months (B,E) and 24 months (C,F) after the surgery (arrow).

plate. Unfortunately, they migrated on POD 17, and were replaced by a mesh cage. Kaloostian et al. (17) described a case of en bloc spondylectomy for a C2 chordoma, the dislodgement of the cage caused significant compression of the supralaryngeal region with imminent airway obstruction 4 months after the surgery. In a retrospectively study published by our institution (5), we shared our experience with 19 consecutive cases of primary upper cervical tumors treated with spondylectomy, among the 18 patients with available radiographic materials, instrumentation failure or nonfusion occurred in 6 cases. Nine patients achieved fusion with intact internal instrumentation, while 3 patients achieved fusion with the anterior construct in a tilting position. In 2016, we reported the first case of upper cervical reconstruction using the $3 \mathrm{D}$ printed vertebral body (8). At the 12-month follow-up, he had no symptoms of mechanical pain, his daily life had no obvious restrictions, and imaging studies revealed evidence of implant osseointegration without subsidence or displacement. Although the patient died of systemic metastasis 15 months after the surgery, no evidence of local recurrence and instrumentation related complications was observed. Based on the experience of this case, our institution continues to improve this technique and apply it to other patients under the approval of the ethics committee.

In our study, the tumors were removed piecemeal although the capsules were kept intact until the edges were clearly exposed. En bloc spondylectomy has been widely used for aggressive benign and malignant tumors located in the thoracolumbar spine. However, in the upper cervical spine, the important local anatomical structures, including the vertebral arteries, cervical spinal cord, and nerve roots make en bloc resection challenging. Sacrifice of vertebral artery may result in serious complications (18-20). When both vertebral arteries are involved, en bloc resection is impossible to perform (4 cases in our study). The intralesional gross total resection that intentionally transgressed to oncological principles and made up by postoperative radiotherapy may serve as a more technically feasible option to limit complications $(7,21,22)$.

The new reconstruction option may have some advantages over conventional methods. First, it could 
provide reliable primary immediate postoperative stability. Given the nature of tailoring to individual anatomical characteristics based on CAD models, it provides a larger contact area and a superior match to the adjacent bony surfaces. For conventional titanium mesh cage, the sharp edge may lead to cage subsistence, endplate fracture, or implant collapse (23). Moreover, the screw tracks were integrated into the artificial vertebra, resulting in "selfstabilization". Although a spondylectomy was performed, the patients were all allowed to ambulate on POD 1 with a Philadelphia collar except for the first case.

Secondly, the anatomical design of the contact surface of the curved porous endplate and its biocompatibility provided reliable mid-long-term stability. The porous bone-contacting surface of the 3D-printed vertebral body is conducive to bone in-growth into the trabecular pores to achieve firm osseointegration, which was supported by evidence from previous basic research and in vivo studies $(15,16,24)$. In our study, no bone graft was used. The additional trauma, potential complications following autologous bone graft harvesting were avoided. What's more, the 3D-printed vertebral body may be less affected by postoperative radiotherapy because solid combination was accomplished as long as the osseointegrations on the two ends were achieved. Postoperative radiotherapy, serving as a common adjuvant therapy, has shown to increases the risk of instrumentation failure for conventional reconstruction methods in many studies (25-27). In our study, the progress of osseointegration is evident on follow-up with imaging studies. On lateral radiography, regenerated osseous tissue was seen adhering to the $3 \mathrm{D}$-printed vertebral body (Figures $2 B, 4 B, C)$. Sagittal CT revealed new bone tissue crawling and growing around the ends of the $3 \mathrm{D}$-printed vertebral body from the upper and lower vertebra (Figures $2 D, 4 E, F$ ). All patients were capable of resuming normal activity without mechanical pain associated with spinal instability at 12-month follow-up.

Finally, the use of $3 \mathrm{D}$-printed vertebral body may reduce the need for transoral or transmandibular approach in some cases. Based on our experience (5), we chose to perform C2 spondylectomy using the posterior-anterior approach. The vertebral arteries could be isolated more easily and safely. Additionally, the occipitocervical fixation can provide reliable stability during repositioning. However, the disadvantage of the occipitocervical fixation is that a transoral or transmandibular approach may be typically required because the mandible cannot extend after posterior occipitocervical fixation which may lead to posterior pharyngeal complications that significantly affect the patients' postoperative adjuvant therapy and life quality $(6,28)$. Based on the therapeutic experience of the first 4 cases, we developed confidence regarding the stability of the implant, and shorter posterior fixation from $\mathrm{C} 1$ to the inferior vertebrae was attempted in the latter cases. It appeared that the anterior reconstruction with $3 \mathrm{D}$-printed implant was strong enough that the atlanto-occipital joint could be preserved; it ensured full extension of the mandible to facilitate the anterior high retropharyngeal approach during the second-stage surgery (Figure 3D). Beyond that, the retention of the atlanto-occipital joint provided a superior function-wise outcome compared to the conventional approach of posterior occipital-cervical fixation, as most of the flexion-extension of the head was achieved by the movement between the atlas and occiput.

However, there are some limitations of this technology. First, once the treatment plan is made and the custom-made implant is fabricated, some unplanned change may take mismatch between the defect and the implant. Second, in order to prevent deviations between the plan and the actual situation, 3 implants with a size difference of $1 \mathrm{~mm}$ were prepared for each patient to fit the actual intraoperative bone defect. Although we only charged for one, it increased the cost to some extent.

\section{Conclusions}

With the development of 3D-printed technology, the application of spinal implants is progressing toward customization and tailoring to individual patient needs. Our study suggests that 3D-printed implant may be a good option in upper cervical reconstruction, the tailored shape matching with the contact surfaces and the porous structure conductive to osseointegration provide both short- and long-term stability to the implant. However, a higher level of evidence is still needed.

\section{Acknowledgments}

Funding: This study was partially funded by Peking University Third Hospital, Grant no. BYSY2017002.

\section{Footnote}

Conflicts of Interest: NX serves as an unpaid section editor member of Annals of Translational Medicine from Oct 2019 to Sep 2020. The other authors have no conflicts of interest 
to declare.

Ethical Statement: The authors are accountable for all aspects of the work in ensuring that questions related to the accuracy or integrity of any part of the work are appropriately investigated and resolved. The research was in compliance of the Declaration of Helsinki and was approved by the institutional review board of Peking University Third Hospital (ID: 12-13-QX-GIC).

Open Access Statement: This is an Open Access article distributed in accordance with the Creative Commons Attribution-NonCommercial-NoDerivs 4.0 International License (CC BY-NC-ND 4.0), which permits the noncommercial replication and distribution of the article with the strict proviso that no changes or edits are made and the original work is properly cited (including links to both the formal publication through the relevant DOI and the license). See: https://creativecommons.org/licenses/by-nc-nd/4.0/.

\section{References}

1. Kerr DL, Dial BL, Lazarides AL, et al. Epidemiologic and survival trends in adult primary bone tumors of the spine. Spine J 2019;19:1941-9.

2. Scheer JK, Tang J, Eguizabal J, et al. Optimal reconstruction technique after $\mathrm{C}-2$ corpectomy and spondylectomy: a biomechanical analysis. J Neurosurg Spine 2010;12:517-24.

3. Hsieh PC, Gallia GL, Sciubba DM, et al. En bloc excisions of chordomas in the cervical spine: review of five consecutive cases with more than 4-year follow-up. Spine (Phila Pa 1976) 2011;36:E1581-7.

4. Rhines LD, Fourney DR, Siadati A, et al. En bloc resection of multilevel cervical chordoma with $\mathrm{C}-2$ involvement. Case report and description of operative technique. J Neurosurg Spine 2005;2:199-205.

5. Wei F, Liu Z, Liu X, et al. An Approach to Primary Tumors of the Upper Cervical Spine With Spondylectomy Using a Combined Approach: Our Experience With 19 Cases. Spine (Phila Pa 1976) 2018;43:81-8.

6. Wewel JT, Nunna RS, Tan LA, et al. Novel reconstruction of the anterior craniocervical junction using an expandable cage with integrated fixation after total C2 spondylectomy for chordoma. J Clin Neurosci 2016;30:157-60.

7. Suchomel P, Buchvald P, Barsa P, et al. Single-stage total C-2 intralesional spondylectomy for chordoma with threecolumn reconstruction. Technical note. J Neurosurg Spine
2007;6:611-8.

8. Xu N, Wei F, Liu X, et al. Reconstruction of the Upper Cervical Spine Using a Personalized 3D-Printed Vertebral Body in an Adolescent With Ewing Sarcoma. Spine (Phila Pa 1976) 2016;41:E50-4.

9. Wu AM, Lin JL, Kwan K, et al. 3D-printing techniques in spine surgery: the future prospects and current challenges. Expert Rev Med Devices 2018;15:399-401.

10. Girolami M, Boriani S, Bandiera S, et al. Biomimetic 3D-printed custom-made prosthesis for anterior column reconstruction in the thoracolumbar spine: a tailored option following en bloc resection for spinal tumors: Preliminary results on a case-series of 13 patients. Eur Spine J 2018;27:3073-83.

11. Wei R, Guo W, Ji T, et al. One-step reconstruction with a 3D-printed, custom-made prosthesis after total en bloc sacrectomy: a technical note. Eur Spine J 2017;26:1902-9.

12. Enneking WF. A system of staging musculoskeletal neoplasms. Clin Orthop Relat Res 1986;(204):9-24.

13. Kirshblum SC, Burns SP, Biering-Sorensen F, et al. International standards for neurological classification of spinal cord injury (revised 2011). J Spinal Cord Med 2011;34:535-46.

14. Oken MM, Creech RH, Tormey DC, et al. Toxicity and response criteria of the Eastern Cooperative Oncology Group. Am J Clin Oncol 1982;5:649-55.

15. Xiu P, Jia Z, Lv J, et al. Tailored Surface Treatment of 3D Printed Porous Ti6Al4V by Microarc Oxidation for Enhanced Osseointegration via Optimized Bone InGrowth Patterns and Interlocked Bone/Implant Interface. ACS Appl Mater Interfaces 2016;8:17964-75.

16. Yang J, Cai H, Lv J, et al. In vivo study of a self-stabilizing artificial vertebral body fabricated by electron beam melting. Spine (Phila Pa 1976) 2014;39:E486-92.

17. Kaloostian PE, Gokaslan ZL. Surgical management of primary tumors of the cervical spine: surgical considerations and avoidance of complications. Neurol Res 2014;36:557-65.

18. Bailey CS, Fisher CG, Boyd MC, et al. En bloc marginal excision of a multilevel cervical chordoma. Case report. J Neurosurg Spine 2006;4:409-14.

19. Choi D, Melcher R, Harms J, et al. Outcome of 132 operations in 97 patients with chordomas of the craniocervical junction and upper cervical spine. Neurosurgery 2010;66:59-65; discussion 65.

20. Lee CH, Hong JT, Kang DH, et al. Epidemiology of Iatrogenic Vertebral Artery Injury in Cervical Spine Surgery: 21 Multicenter Studies. World Neurosurg 
2019;126:e1050-4.

21. Štulík J, Kozák J, Šebesta P, et al. Total spondylectomy of C2: report of three cases and review of the literature. J Spinal Disord Tech 2010;23:e53-8.

22. Sar C, Eralp L. Transoral resection and reconstruction for primary osteogenic sarcoma of the second cervical vertebra. Spine (Phila Pa 1976) 2001;26:1936-41.

23. Chen Y, Chen D, Guo Y, et al. Subsidence of titanium mesh cage: a study based on 300 cases. J Spinal Disord Tech 2008;21:489-92.

24. Fukuda A, Takemoto M, Saito T, et al. Osteoinduction of porous Ti implants with a channel structure fabricated by selective laser melting. Acta Biomater 2011;7:2327-36.

25. Matsumoto M, Watanabe K, Ishii K, et al. Complicated

Cite this article as: Wei F, Li Z, Liu Z, Liu X, Jiang L, Yu M, Xu N, Wu F, Dang L, Zhou H, Li Z, Cai H. Upper cervical spine reconstruction using customized $3 \mathrm{D}$-printed vertebral body in 9 patients with primary tumors involving C2. Ann Transl Med 2020;8(6):332. doi: 10.21037/atm.2020.03.32 surgical resection of malignant tumors in the upper cervical spine after failed ion-beam radiation therapy. Spine (Phila Pa 1976) 2010;35:E505-9.

26. Park SJ, Lee CS, Chang BS, et al. Rod fracture and related factors after total en bloc spondylectomy. Spine J 2019;19:1613-9.

27. Sciubba DM, De la Garza Ramos R, Goodwin CR, et al. Total en bloc spondylectomy for locally aggressive and primary malignant tumors of the lumbar spine. Eur Spine J 2016;25:4080-7.

28. Guppy KH, Chakrabarti I, Isaacs RS, et al. En bloc resection of a multilevel high-cervical chordoma involving C-2: new operative modalities: technical note. J Neurosurg Spine 2013;19:232-42. 